\title{
Lower Gastrointestinal Hemorrhage, CTCAE
}

National Cancer Institute

\section{Source}

National Cancer Institute. Lower Gastrointestinal Hemorrhage, CT CAE. NCI Thesaurus.

Code C143656.

A disorder characterized by bleeding from the lower gastrointestinal tract (small intestine, large intestine, and anus). 